\section{Neurological Disease in Carlisle}

Not so long ago the term epidemiology would have been applied entirely to communicable diseases. But latterly its methods have been applied with success to the study of many non-infectious conditions, including some in the nervous system. Some good examples of this are R. S. Allison and J. H. D. Millar's ${ }^{1}$ studies of the prevalence of disseminated sclerosis in Northern Ireland and the former author's studies in collaboration with $M$. Alter and colleagues ${ }^{2}$ of the comparative prevalence of the disease in Nova Scotia and South Carolina.

If we are to detect an unusual prevalence of, or freedom from, a given disease, the expected frequency of its occurrence in a community must be known. Data obtained from hospital records refer to patients with special characteristics and can give misleading figures of the true incidence. Mary Brewis and colleagues ${ }^{3}$ have now published the results of a survey of neurological disease as it occurs in the City of Carlisle. This city had a population of 70,000 at the time of the survey, and the authors show that the community was a representative cross-section of the population of England and Wales. They studied hospital records, records kept by general practitioners, private records of three consultant physicians, certain records of the medical officer of health, and death certificates. In addition they carried out a survey of a random sample (11.5\%) of households to assess the incidence of minor disorders such as migraine, attacks of loss of consciousness, and others, which might not be included in hospital statistics. Having collected and analysed the data the authors report the frequency and incidence of new cases of some neurological diseases in the years 1955-61 and of established cases of these diseases on 1 January 1961.

When figures for England and Wales as a whole are derived from the Carlisle sample we find that there would be about 253,000 cases of epilepsy in the country, with an annual incidence of 13,000 . The disease occurred in $0.6 \%$ of the population, but true petit mal epilepsy was comparatively rare, representing only $6 \%$ of the total. There would be 53,000 cases of Parkinson's disease, 37,000 of disseminated sclerosis (2,000 new cases per year), and 35,000 cases of neurosyphilis. It was perhaps surprising to find figures to suggest there would be as many as 16,000 cases of subacute combined degeneration throughout the country. Needless to say, cerebrovascular disease accounted for $85 \%$ of deaths attributable to neurological disease and was the second zommonest cause $(16 \%)$ for all deaths. The houschold survey gave a prevalence for migraine of 33 per 1,000 of those interviewed, females being affected three times more than males. Women suffered more from all types of headaches than men with one exception-post-traumatic headache. The incidence of Parkinsonism confirmed the impression held by many clinicians that it is more common in fact than the records from hospitals or even general practitioners suggest. Figures for many other conditions are also given.

There are few comparable studies. L. T. Kurland's ' similar study in Rochester, Minnesota, applied to a smaller population and was subject to the special influence of the Mayo Clinic, but his rates are often extrapolated to apply to the United States as a whole. These give figures similar

\footnotetext{
' Allison, R. S., and Millar, J. H. D., Ulster med. F., 1954, 23, Suppl. No. 2 .

' Alter, M., Allison, R. S., Talbert, O. R., and Kurland, L. T., Wld Neurol., 1960, 1, 55

- Brewis, M., Poskanzer, D. C., Rolland, C., and Miller, H., Acta neurol. scand., 1966, 42, Suppl. No. 24, 1 .

Kurland, L. T., f. chron. Dis., 1958, 8, 378
}

to those in the British study for several diseases, the rate for epilepsy, for instance, being identical.

The great value of the present survey is that it gives a baseline from which to compare the incidence of a given disease in some other community, which might be under some special social, racial, climatic, or geographical influences. A rising incidence can be detected and false impressions can be avoided. The authors have, for instance, found nothing to confirm the suggestion that disseminated sclerosis is more prevalent in rural than in urban communities. But there is the danger that when small figures are studied they cannot reliably be applied to a nation, for an increase of one case per year may add thousands to the national total. The authors are acutely aware of this, and the extrapolation was not applied to any condition having a rate of less than 20 cases per 100,000 population. A study such as this also offers the opportunity for reappraisal of the direction to which research activities might be directed to try to bring benefit to the greatest number of people. Much human suffering as well as loss of earning capacity results from disorders passed over because of their so-called minor nature, while money is often poured into research into more dramatic diseases which affect a very small proportion of the community. It is hoped that this survey may be followed by others in geographically and racially entirely different communities, for if a true comparison can be obtained it would provide some exceedingly interesting figures.

\section{"Cardiovascular Research"}

Following hard on the heels of the British fournal of Medical Education, the first number of which appeared last month, comes Cardiovascular Research, the eighteenth specialist journal to be published in association with the British Medical fournal. The first issue of Cardiovascular Research ${ }^{1}$ came $^{2}$ out on 13 January. Publication will be quarterly.

The study of heart disease has for long exercised a special attraction on some of the finest brains in medicine in Great Britain, and in recent years these physicians have been joined by surgeons of world renown. Therapy has made dramatic advances in the last two decades, and the enormous amount of laboratory and clinical research on which they are based has resulted in a spate of published papers. As Professor J. P. Shillingford, editor of Cardiovascular Research, explains in the first issue, many have hitherto found a place in the British Heart fournal, another journal published in association with the B.M.F. and, like the new one, under the auspices of the British Cardiac Society. For some time it has seemed that the papers reporting basic research, especially laboratory work, might be more suitably grouped together, leaving the British Heart fournal to publish those of more direct clinical interest. The two journals will thus to a large extent be complementary.

In addition to cardiologists the new journal should appeal to biochemists, pharmacologists, and cardiovascular surgeons, to name only the more obvious groups of workers. Research papers of the usual kind will of course occupy much of the space, but the journal will also provide rapid publication for preliminary communications and contain reports on new instruments and techniques. Intending contributors should submit their manuscripts to Professor J. P. Shillingford, Cardiovascular Research, B.M.A. House, Tavistock Square, London W.C.1.

Dublished by the British Medical Association, London. Annual subscription $£ 33$ s. (abroad $£ 3$ 10s. ; U.S.A. \$10). 